\title{
LA PROTECCIÓN DEL PATRIMONIO CULTURAL SUBACUÁTICO EN LA CONVENCIÓN SOBRE LA PROTECCIÓN DEL Patrimonio Cultural Subacuático de 2001*
}

\section{RUbÉN MiRANDA GoNÇALVES ${ }^{* *}$}

RESUMEN: Este artículo aborda el desarrollo de la norma que llenó un vacío jurídico existente en la materia objeto de análisis. A lo largo de este estudio se analizará el régimen jurídico de la Convención del Patrimonio Cultural Subacuático de 2001, estudiando su nacimiento, los objetivos y principios generales que establece, y la protección del patrimonio cultural subacuático en los distintos espacios marinos. Por último, se hará referencia a la entrada en vigor de la misma y a la relación de Estados que la han ratificado o aprobado. El objeto de análisis es especialmente relevante ya que debe considerarse que hasta el año 2001 no existía ningún texto internacional que protegiese esta materia de manera específica.

PALABRAS CLAVE: Patrimonio cultural subacuático - Convención sobre la protección del Patrimonio Cultural Subacuático - Derecho Público - expoliación - Derecho del mar.

\section{THE PROTECTION OF THE UNDERWATER CULTURAL HERITAGE IN THE CONVENTION ON THE PROTECTION OF THE UNDERWATER CUlTURAL HERITAGE 2001}

ABSTRACT: This article discusses the development of the rule that filled a legal vacuum on this matter. Throughout this study, the legal status of the Underwater Cultural Heritage Convention 2001 will be analyzed, such as the studying of its birth, objectives and the general principles that establishes and the protection of the underwater cultural heritage in various marine areas. Finally, its entry into force will and the relation of states that have ratified or approved it will be highlighted. The object of

\footnotetext{
* $\quad$ Fecha de recepción: 18 de junio de 2016.

Fecha de aceptación: 26 de septiembre de 2016.

** Doctorando en Derecho Administrativo en la Universidad de Santiago de Compostela. Profesor de Derecho Administrativo en el Máster de Abogacía de la Universidad Europea de Madrid y profesor en el Postgrado en Seguridad Internacional de la Universidad de Santiago de Compostela. Ruben.miranda@usc.es
} 
analysis is especially relevant since it should be noted that until 2001 there wasn't international text that would protect this area specifically.

KEY WORDS: Underwater cultural heritage - Convention on the protection of the Underwater Cultural Heritage - Public Law - spoliation Law of the Sea.

Sumario: 1) Nacimiento y creación. 2) Objetivos y principios generales de la Convención de 2001. 3) Protección del patrimonio cultural subacuático en los distintos espacios marinos según la Convención de 2001. (3.1.) La división juridica del espacio marino. (3.2.) El patrimonio cultural subacuático situado en las aguas interiores, archipelágicas y mar territorial. (3.3.) El patrimonio cultural subacuático situado en la Zona Contigua. (3.4.) El patrimonio cultural subacuático situado en Zona Económica Exclusiva y Plataforma Continental. (3.5.) El patrimonio cultural subacuático situado en la Zona de fondos marinos y oceánicos. 4) Entrada en vigor de la Convención de 2001. Conclusiones.

\section{1) NACIMIENTO Y CREACIÓN}

Antes de entrar de lleno en el análisis de la Convención de 2001, parece necesario explicar cómo se llegó hasta ella y el porqué de su nacimiento y creación.

Hasta la entrada en vigor de la Convención que vamos a estudiar, no había ninguna norma en el ámbito internacional que protegiese esta materia, aunque fueron varias las ocasiones en que se intentó hacerlo, sin que se llegase a formalizar nada en concreto. Sí existían algunas recomendaciones pero, como bien apunta Castillo Belinchón, "se carecía de un instrumento jurídico internacional que regulara esta materia” ${ }^{1}$.

Sin duda alguna, el Patrimonio Cultural Subacuático ${ }^{2}$ es un claro atractivo para el saqueo y el expolio, ya que en el fondo marino se pueden encontrar piezas de valor incalculable que, de no existir una normativa que lo proteja, incentivaría a mucha gente e incluso a muchas a empresas

1 Castillo Belinchón, Rocío (2008) "El patrimonio cultural subacuático". ARQVA, Museo Nacional de Arqueología Subacuática: catálogo. Madrid: Ministerio de Cultura-Secretaría General Técnica, p. 40.

2 El artículo 1.1 de la Convención define el patrimonio cultural subacuático como: "todos los rastros de existencia humana que tengan un carácter cultural, histórico o arqueológico, que hayan estado bajo el agua, parcial o totalmente, de forma periódica o continua, por lo menos durante 100 ańos, tales como: (i) los sitios, estructuras, edificios, objetos y restos humanos, junto con su contexto arqueológico y natural;(ii) los buques, aeronaves, otros medios de transporte o cualquier parte de ellos, su cargamento u otro contenido, junto con su contexto arqueológico y natural; y(iii) los objetos de carácter prehistórico”. 
a buscar provecho de las mismas. Como dato curioso, Fuentes Camacho indica que el perfil del expoliador no es igual en todos los casos y señala que pueden distinguirse tres grandes grupos de sujetos: expoliadores, intermediarios y adquirentes finales ${ }^{3}$.

Ello condujo a una realidad incuestionable y es que, como bien apunta Bou Franch, "todo el patrimonio cultural subacuático se encuentra en la actualidad [...] amenazado de muerte" ${ }^{4}$. Esto se debe a numerosos factores, entre los que se pueden destacar: el saqueo y la expoliación por parte de la población y también "la difusión generalizada de las bombonas de oxígeno comprimido y de las escafandras autónomas entre los submarinistas [...] y la utilización y difusión de instrumentos de detección remota, sobre todo el uso de detectores de objetos metálicos" que llevan al propio saqueo y expolio de los bienes que se encuentran sumergidos ${ }^{6}$.

Como consecuencia de todo lo anterior, la UNESCO fue consciente de que tenía que buscar una solución. Todo el patrimonio cultural sumergido se encontraba en un verdadero peligro y, aunque existían normas internacionales que hacían ciertas referencias, como puede ser la Convención de las Naciones Unidas sobre el Derecho del Mar-que no es un instrumento que proteja al patrimonio cultural subacuático-, desde la UNESCO se acordó que había que crear una norma concreta que regulase la materia.

El origen de esta Convención hay que buscarlo, según indica Aznar Gómez, en un foro de la International Law Association "que en 1988 ya había establecido en su seno un Comité sobre el derecho del patrimonio cultural y que un año más tarde nombre a los profesores Patrick O'KeEFe y James NAfZiger como presidente y relator, respectivamente, del comité que empezaría a redactar un Proyecto de convención sobre el patrimonio cultural subacuático"7.

3 Fuentes Camacho, Víctor (1993) El tráfico ilicito internacional de bienes culturales. Madrid: Beramar, pp. 33 y ss.

4 Bou Franch, Valentín (2009) "La Convención de la UNESCO sobre la protección cultural subacuática”. En La protección juridico internacional del patrimonio cultural. Especial referencia a España. Madrid: Colex, p. 192.

5 Bou (2009) 192.

6 Puede traerse a colación el caso Odyssey y la fragata de guerra española "Nuestra Señora de las Mercedes", que supuso uno de los mayores expolios de patrimonio cultural subacuático. Esta empresa, Odyssey, expolió 17 toneladas de plata acuñada en 594.000 monedas, entre otras reliquias. Tras el correspondiente litigio, se reconoció que todo lo sustraído correspondía a España y fue devuelto al Estado español todo el patrimonio. Puede consultarse más información en Álvarez Rubial, Pablo (2012) "Proceso judicial del caso Odyssey en Estados Unidos”. Disponible en: http://noticias.juridicas.com/conocimiento/articulosdoctrinales/4745-el-proceso-judicial-del-caso-odyssey-en-estados-unidos-/ [fecha de visita: 20 de marzo de 2016].

7 Aznar Gómez, Mariano José (2004) La protección Internacional del Patrimonio Cultural Subacuático con especial referencia al caso de España. Valencia: Tirant lo Blanch, p. 209. 
Se presentó a la UNESCO para que esta lo sometiese a su análisis y, tras la adopción de la Decisión 5.5.1 que aprobó el Consejo Ejecutivo en la 146a sesión, se decidió nombrar a un grupo de expertos sobre la materia para estudiarlo. Después de varias reuniones de expertos -se llegaron a hacer hasta cuatro reuniones de expertos gubernamentales ${ }^{8}-$, no se llegó a ningún acuerdo en concreto, debido a que había puntos con consenso y otros con discrepancias.

El asunto sobre el que no hubo discrepancias fue el relativo a la protección de todo el patrimonio cultural subacuático sin entrar en cuestiones de título o derechos de propiedad ${ }^{9}$.

Caso contrario, y objeto de duras discrepancias, fueron "la exclusión o no de los pecios de los buques de guerra [...], los asuntos jurisdiccionales, es decir, sobre todo el régimen jurídico de los objetos arqueológicos e históricos que se encontrasen más allá de la zona contigua pero antes de entrar en la Zona internacional de fondos marinos, [...] y el reconocimiento o no de competencias o derechos al Estado ribereño y, en su caso, si ello suponía o no una derogación del régimen de la Convención de las Naciones Unidas sobre el Derecho del Mar de 1982"10, entre otras.

Como ya hemos señalado, tras varias reuniones de expertos gubernamentales durante los años 1996, 1998, 1999 y 2001, finalmente, en esta última, y en el seno de la $31^{\text {a }}$ Conferencia General, se aprobó la Convención el día 2 de noviembre de 2001 recibiendo 87 votos a favor, 4 en contra y 22 abstenciones ${ }^{11}$, aunque, como veremos, esta solo entró en vigor el día 2 de enero de $2009^{12}$.

Por lo que afecta a España, hay que destacar que fue uno de los primeros países que la ratificó, concretamente el día 6 de junio de 2005, y con ello, como señala Aznar Gómez, "lanzaba un mensaje político «queremos proteger el patrimonio cultural subacuático en el marco cooperativo de la Convención» al resto de Estados"13.

\section{Bou (2009) 196.}

Bou (2009) 196. Nota al pie $\mathrm{N}^{\circ} 13$.

Bou (2009) 196 y ss.

Puede verse el acta en el siguiente enlace, concretamente en lo que nos afecta, p. 561 in fine, cuando interviene la Secretaria. Disponible en: http://unesdoc.unesco.org/ images/0012/001289/128966m.pdf [fecha de visita: 4 de abril de 2016]. Los cuatro votos negativos se corresponden a Rusia, Noruega, Turquía y Venezuela. Las abstenciones corresponden a Alemania, Brasil, Colombia, Francia, Grecia, Ginea-Bissau, Islandia, Israel, Países Bajos, Paraguay, Reino Unido, República Checa, Suecia, Suiza y Uruguay.

12 Puede complementarse la información al respecto en ScovazzI, Tulio (2001) The 2001 UNESCO Convention on the protection of the underwater cultural heritage, 11 IYIL, pp. 9 y ss. Y también Forrest, Craig (2002) A Nes International Regime for the Protection of Underwater Cultural Heritage, 34 ICLQ, pp. 511 y ss.

13 Aznar Gómez, Mariano José (2011) "Protección en el espacio iberoamericano del patrimonio subacuático y convenios de la UNESCO”. En La UNESCO y la protección internacional de la cultura en el espacio iberoamericano. Madrid: Thomson Reuters, p. 139. 


\section{2) OBJETIVOS Y PRINCIPIOS GENERALES DE LA CONVENCIÓN DEL 2001}

La Convención de 2001 se compone de 35 artículos y un anexo con 36 normas que el artículo 33 de la Convención califica como "parte integrante de ella" 14 .

En el artículo 2 de la misma se encuentran los objetivos, entre los que se destacan "garantizar y fortalecer la protección del patrimonio cultural subacuático" y preservarlo en "beneficio de la humanidad".

Los principios generales que aparecen en el artículo 2 de la Convención están desarrollados, a su vez, en las normas que se encuentran en el anexo de la misma. La primera norma indica que la prioridad para proteger el patrimonio cultural será la conservación in situ ${ }^{15}$. Además, en este principio se hace referencia a las "actividades dirigidas al patrimonio cultural subacuático", que a su vez, son definidas en el artículo 1.6 de la Convención como aquellas "cuyo objeto primordial sea el patrimonio cultural subacuático y que puedan, directa o indirectamente, alterarlo materialmente o causarle cualquier otro daño".

En relación con estas actividades, la norma tres de la Convención señala que "no deberán perjudicarlo más de lo que sea necesario para los objetivos del proyecto". Esta norma tiene sentido, ya que, como bien apunta Luna ErReguerena, cuando se realiza cualquier trabajo arqueológico en un sitio, es inevitable causar algún tipo de daño ${ }^{16}$. En la norma cuatro se prevé que las actividades dirigidas al patrimonio cultural subacuático "deberán servirse de técnicas y métodos de exploración no destructivos". Como dice la autora citada anteriormente, "esto, evidentemente, permitirá que el sitio conserve el contenido cultural original que mantuvo celosamente guardado durante tanto tiempo e incrementará las posibilidades de investigarlo de manera científica"17.

En el caso de que fuese necesaria la realización de ciertos estudios científicos o la protección definitiva del patrimonio cultural subacuático, la misma norma cuatro indica que "las técnicas y los métodos empleados deberán ser lo menos dañinos posible y contribuir a la preservación de los vestigios". En relación con ella estaría la norma número cinco, que indi-

\footnotetext{
$14 \quad$ Artículo 33 Convención de 2001.

15 "La conservación in situ será considerada la opción prioritaria para proteger el patrimonio cultural subacuático. En consecuencia, las actividades dirigidas al patrimonio cultural subacuático se autorizarán únicamente si se realizan de una manera compatible con su protección y, a reserva de esa condición, podrán autorizarse cuando constituyan una contribución significativa a la protección, el conocimiento o el realce de ese patrimonio".

16 Luna Erreguerena, Pilar (2009) "A importância do anexo da convenção patrimônio cultural subaquático". En Patrimônio Cultural e Ambiental. questôes legais e conceituais, Annablume. São Paulo: Annablume, p. 50. LUNA (2009) 51.
} 
rectamente nos remite a las anteriores y puntualiza que dichas actividades "evitarán perturbar innecesariamente los restos humanos o los sitios venerados".

Al mismo tiempo, el artículo 2, apartado séptimo, establece que el patrimonio cultural subacuático no será objeto de explotación comercial y la norma número dos lo desarrolla estipulando que no está permitida la "explotación comercial de patrimonio cultural subacuático que tenga por fin la realización de transacciones, la especulación o su dispersión irremediable". Respecto a esta cuestión, Bou Franch apunta que "sin embargo, esta afirmación de principio no prohíbe la prestación de servicios arqueológicos profesionales o de servicios conexos necesarios cuya índole y finalidad sean plenamente conformes con la Convención de la UNESCO, y tengan la autorización de las autoridades competentes. Tampoco prohíbe el depósito del patrimonio cultural subacuático recuperado en el marco de un proyecto de investigación ejecutado de conformidad con esta Convención, siempre que dicho depósito cumpla una amplia serie de condiciones" 18 .

Para finalizar, conviene hacer mención al artículo 2 en su apartado segundo, que señala que "los Estados Partes cooperarán en la protección del patrimonio cultural subacuático”.

\section{3) PROTECCIÓN DEL PATRIMONIO CULTURAL SUBACUÁtiCO EN LOS DISTINTOS ESPACIOS MARINOS SEGÚN LA CONVENCIÓN DE 2001}

\section{(3.1.) LA DIVISIÓN JURÍDICA DEL ESPACIO MARINO}

Antes de entrar en el análisis de la protección del patrimonio cultural subacuático en los distintos espacios marinos que aparece en la Convención de 2001, conviene hacer unas anotaciones previas para aclarar algunos conceptos que pueden resultar complejos si no se tiene un conocimiento sobre la materia. No explicaremos con profundidad la clasificación del espacio marítimo, porque no es objeto de nuestro estudio, pero sí daremos unas pinceladas muy breves para poder ubicarse.

En el espacio marino se pueden encontrar varias partes: aguas interiores, mar territorial, zona contigua, plataforma continental, zona económica exclusiva y alta mar.

Las aguas interiores, según el artículo 8.1 de la Convención de Naciones Unidas sobre Derecho del Mar y el artículo 5 de la Convención de Ginebra sobre mar territorial y zona contigua, son aquellas que están

\footnotetext{
18 Bou (2009) 200.
} 
situadas "en el interior de la línea de base del mar territorial"19. Su límite exterior coincide con el límite interior del mar territorial y su límite interior coincide con tierra firme.

Por su parte, el mar territorial, cuya anchura aparece recogida en el artículo 3 de la CNUDM, es aquel que se extiende hasta un máximo de doce millas marinas contadas desde las líneas de base. Además, al igual que en las aguas interiores, el Estado ejerce plena soberanía en él ${ }^{20}$. En el caso español, nuestra ley 10/1977, de 4 de enero, sobre mar territorial, cumple con lo dispuesto en la normativa internacional y fija una anchura de 12 millas náuticas desde las líneas de base.

Posteriormente se encuentra la zona contigua, que es el espacio marino que sigue inmediatamente al mar territorial y abarca otras doce millas marinas desde el mar territorial y veinticuatro desde las líneas de base, institución recogida en el artículo 33 de la CNUDM y el artículo 24 de la Convención de Ginebra citada anteriormente, que la define como la "zona de alta mar contigua a su mar territorial".

Otra de las partes del espacio marítimo es la plataforma continental, que aparece regulada en el artículo 76 de la CNUDM a cuyo tenor "la plataforma continental de un Estado ribereño comprende el lecho y el subsuelo de las áreas submarinas que se extienden más allá de su mar territorial y a todo lo largo de la prolongación natural de su territorio hasta el borde exterior del margen continental, o bien hasta una distancia de 200 millas marinas contadas desde las líneas de base a partir de las cuales se mide la anchura del mar territorial”.

También forma parte del espacio marino la zona económica exclusiva o ZEE que, según el artículo 55 de la CNUDM, "es un área situada más allá del mar territorial y adyacente a este”. Además, el artículo 57 del mismo texto legal hace alusión a que su anchura es de "200 millas marinas contadas desde las líneas de base a partir de las cuales se mide la anchura del mar territorial”.

Por último, se encontraría la alta mar, cuya definición podemos encontrar en el artículo 1 de la Convención de Ginebra sobre Alta Mar, de 29 de abril de 1958, a cuyo tenor "se entenderá por «alta mar» la parte del mar no perteneciente al mar territorial ni a las aguas interiores de un Estado", concepto que fue ampliado en la Tercera Conferencia sobre el Derecho del Mar excluyéndose además del mar territorial y las aguas interiores, la zona económica exclusiva y las aguas archipelágicas.

19 Las líneas de base son aquellas desde las cuales se mide el mar territorial y las demás zonas marítimas (Artículo 3 de la Convención de Ginebra sobre mar territorial y zona contigua). La línea de base normal, "es la línea de bajamar a lo largo de la costa" (artículo 5 CNUDM).

20 Jiménez Piernas, Carlos (2013) "Régimen jurídico de los espacios marinos (I): aguas interiores, mar territorial y zona contigua”. En Díez de Velasco, Manuel (director): Instituciones de Derecho Internacional Público. Madrid: Tecnos, p. 490. 
Explicados estos conceptos básicos, procedemos a continuación al análisis de la protección del patrimonio cultural subacuático que se recoge en la Convención de 2001.

\section{(3.2.) El PATRimonio CUltural Subacuático Situado EN LAS AGUAS INTERIORES, ARCHIPELÁGICAS Y MAR TERRITORIAL}

La Convención de 2001, siguiendo lo recogido en los textos internacionales sobre Derecho del Mar, señala en su artículo 7 que los Estados, en base a su soberanía, "tienen derecho exclusivo de reglamentar y autorizar las actividades dirigidas al patrimonio cultural subacuático en sus aguas interiores, $\operatorname{archipelágicas~}^{21}$ y mar territorial”.

Es tan importante la soberanía de los Estados que la propia Convención establece en su artículo 29 que "al ratificar, aceptar, aprobar la presente Convención o adherirse a ella, un Estado o territorio podrá declarar ante el depositario que la presente Convención no se aplicará a determinadas partes de su territorio, sus aguas interiores, aguas archipelágicas o mar territorial e indicará en esa declaración las razones que la motivan”.

Cualquier objeto arqueológico que forme parte del patrimonio cultural subacuático situado tanto en las aguas interiores, archipelágicas o mar territorial español estará bajo soberanía del Estado Parte, en nuestro caso, el Estado español. En este sentido, sería España quien reglamentaría y autorizaría las actividades dirigidas a su patrimonio cultural subacuático para protegerlo, impidiendo cualquier tipo de intromisión por parte de otro Estado.

Además, el artículo 18 de la Convención indica que cada Estado Parte tiene la obligación de adoptar "medidas destinadas a la incautación de elementos del patrimonio cultural subacuático situado en su territorio, que haya sido recuperado de una manera no conforme" a la Convención de 2001. En este sentido, España estaría legitimada para interceptar a un buque en su mar territorial si le constasen indicios racionales de que lleva, abordo del mismo, objetos que formen parte del patrimonio cultural subacuático español y hacerse con ellos. Aunque en un principio podría colisionar con lo dispuesto en la CNUDM en cuanto al derecho de paso inocente ${ }^{22}$ del que gozan los buques en el mar territorial, la Convención de 2001 lo permite en su artículo 18 apartado primero, ya que

21 Según el artículo 49.1 de la CNUDM, "la soberanía de un Estado archipelágico se extiende a las aguas encerradas por las líneas de base archipelágicas trazadas de conformidad con el artículo 47, denominadas aguas archipelágicas, independientemente de su profundidad o de su distancia de la costa".

22 Derecho que gozan los buques en el mar territorial. Según la CNUDM, ese paso inocente debe reunir una serie de características (artículos 17 y siguientes de la CNUDM). Para considerar que hay paso inocente, este deberá ser rápido e ininterrumpido. El paso es inocente mientras no sea perjudicial para la paz, el buen orden o la seguridad del Estado ribereńo. 
ese objeto sería "recuperado de una manera no conforme con la presente Convención”. Ese patrimonio cultural incautado deberá ser registrado y protegido por el Estado Parte según el artículo 18.2. Asimismo, para seguir protegiéndolo, el Estado Parte, además de velar por darle una disposición acorde con el bien general (artículo 18.4), tiene que notificar la incautación del patrimonio cultural subacuático al Director General de la UNESCO y "a cualquier otro Estado que tenga un vínculo verificable, en especial de índole cultural, histórica o arqueológica con el patrimonio cultural subacuático de que se trate" (artículo 18.3). Se establece, además, la obligación a los Estados Partes de velar por la aplicación de las normas contenidas en el anexo de la Convención en sus aguas interiores, archipelágicas y el mar territorial ${ }^{23}$. Estas últimas disposiciones serían aplicables a todo el patrimonio cultural subacuático, independientemente de la zona en la que se hallare.

\section{(3.3.) El PATRIMONIO CULTURAL SUBACUÁtico SITUADO EN LA ZONA CONTIGUA}

$\mathrm{Al}$ igual que en las aguas interiores, archipelágicas o mar territorial, la Convención de 2001 también prevé que el patrimonio hallado en la Zona Contigua sea protegido. Esta referencia aparece recogida en el artículo 8 de la misma, cuando dispone que "sin perjuicio de lo dispuesto en los Artículos 9 y 10 y con carácter adicional a lo dispuesto en los mismos y de conformidad con el párrafo 2 del Artículo $303^{24}$ de la Convención de las Naciones Unidas sobre el Derecho del Mar, los Estados Parte podrán reglamentar y autorizar las actividades dirigidas al patrimonio cultural subacuático en su zona contigua. Al hacerlo, exigirán que se apliquen las Normas". Lo que quiere decir el artículo 303.2 de la CNUDM es que cualquiera eliminación del patrimonio cultural subacuático que se realice en la Zona Contigua y no lleve aparejada la autorización del Estado ribereño, puede entenderse como una infracción ${ }^{25}$. Los Estados Parte pueden proclamar una Zona Contigua a su mar territorial, siempre que

23 CARducCI, Guido (2002) "The expanding protection of the underwater cultural heritage: The new UNESCO Convention versus existing international law". En The protection of the Underwater Cultural Heritage. Milán: Giuffré, p.188.

24 Según el artículo 303.2 CNUDM, "a fin de fiscalizar el tráfico de tales objetos, el Estado ribereńo, al aplicar el artículo 33, podrá presumir que la remoción de aquellos de los fondos marinos de la zona a que se refiere ese artículo sin su autorización constituye una infracción, cometida en su territorio o en su mar territorial, de las leyes y reglamentos mencionados en dicho artículo".

25 Así lo considera también Strati, Anastasia (1995) The protection of the Underwater Cultural Heritage: An Emerging Objecting of the Contemporary Law of the Sea. La Haya: Kluwer Law International. 
esta no supere las 24 millas náuticas desde las líneas de base y, por tanto, tendrían potestad para sancionar ${ }^{26}$.

Resulta curioso cómo en este precepto se hace uso del término "podrán”, de carácter potestativo, mientras que cuando nos referíamos a las aguas interiores, aguas archipelágicas y mar territorial, hablábamos de un derecho exclusivo (artículo 7). En base a esa potestad, el Estado Parte podrá reglamentar y autorizar las actividades dirigidas al patrimonio cultural subacuático en su Zona Contigua de forma similar a las aguas interiores, archipelágicas y mar territorial, aunque como bien se desprende del tenor literal de este artículo 8, esa reglamentación y autorización tiene que ser acorde con el artículo 303.2 de la CNUDM y, en consecuencia, con los artículos 9 y 10 de la Convención. En este artículo, apunta Bou Franch, "está implícita la idea de que la autorización de la remoción de los objetos arqueológicos e históricos en la Zona Contigua es una competencia exclusiva del Estado ribereño, siempre que este Estado haya previsto tal posibilidad en su legislación interna" 27 . Por tanto, vemos que hay cierta similitud con lo que indicamos en relación con las aguas interiores, archipelágicas y mar territorial, salvando el verbo, teniendo en cuenta que en un caso hablamos de una obligación y, en este caso, de una potestad, siempre que se incluya en la legislación interna del Estado en cuestión.

\section{(3.4.) El PATRIMONIO CULTURAL SUBACUÁTICO SITUADO EN LA ZONA ECONÓMICA EXClUSIVA Y PLATAFORMA CONTINENTAL}

La Convención de 2001 también quiere proteger el patrimonio cultural subacuático que se encuentre en la Zona Económica Exclusiva y en la Plataforma Continental, siendo las dos zonas en donde más cantidad de patrimonio cultural sumergido se puede encontrar y en donde los derechos y obligaciones no estaban resueltos claramente por el derecho en vigor $^{28}$, y lo hace en sus artículos 9 y 10. En ellos se establece la obligación que tienen todos los Estados Parte de proteger el patrimonio cultural subacuático en dichas zonas. El artículo 9 se centra en la información y notificación del patrimonio cultural subacuático hallado en la ZEE y en la PC y el artículo 10 se centra más en la protección del mismo.

En este último se establece que "no se concederá autorización alguna para una actividad dirigida al patrimonio cultural subacuático situado en la Zona Económica Exclusiva o en la Plataforma Continental”, a lo que

\footnotetext{
26 RaU, Markus (2002) "The UNESCO Convention on Underwater Cultural Heritage and the International Law of the See”. En Max Planck Yearbook of United Nations Law. Max Planck Netherlands Fundation, p. 413.

27 Bou (2009) 213.

28 Aznar Gómez, Mariano José (2004) La protección Internacional del Patrimonio Cultural Subacuático con especial referencia al caso de España. Valencia: Tirant lo Blanch, p. 249.
} 
sigue "salvo lo dispuesto en el presente artículo". Lo que a primera vista parece una prohibición no lo es, porque en su apartado segundo se señala que ese Estado parte "tiene derecho a prohibir o a autorizar cualquier actividad dirigida a este patrimonio", cuando con ello se impida cualquier intromisión en sus derechos soberanos o de jurisdicción en la ZEE o la PC.

El único derecho que se le reconoce al Estado Parte o ribereño es el de prohibir o autorizar esas actividades sobre su patrimonio cultural sumergido, siempre que se dé el requisito de "impedir cualquier intromisión en sus derechos soberanos o jurisdicción”.

Otra manera de proteger el patrimonio cultural subacuático en la Zona Económica Exclusiva y en la Plataforma Continental es prohibiendo o autorizando cualquier actividad dirigida a él para impedir cualquier intromisión en sus derechos soberanos o jurisdicción, tal como consta en el artículo 10.2 de la Convención.

Continúa seńalando el artículo 10 en su apartado tercero que, en el caso de descubrirse patrimonio cultural subacuático en la Zona Económica Exclusiva o en la Plataforma Continental de un Estado Parte, o bien cuando se tenga intención de llevar a cabo una actividad dirigida a ese patrimonio cultural sumergido, el Estado Parte tiene que consultar a los demás Estados Parte que hubiesen mostrado interés en consultar cómo asegurar esa protección. Además, este Estado Parte en donde se halla el patrimonio cultural sumergido en cuestión, salvo que renuncie a ello, será el que va a coordinar las consultas.

Como Estado coordinador, indica el artículo 10 en su apartado 4 que para proteger el patrimonio cultural sumergido puede adoptar todas las medidas viables conformes al derecho internacional y/o conceder cualquier autorización para impedir todo peligro inmediato para el patrimonio cultural subacuático, incluido el saqueo. JUste Ruiz apunta que es una de las disposiciones clave del convenio, ya que "sería ilusorio esperar que dichas medidas fueran adoptadas por el Estado del pabellón"29. Además, al Estado coordinador se le encomienda que ponga en práctica las medidas de protección acordadas por los Estados que participen en la consulta, expedirá todas las autorizaciones necesarias con respecto a las medidas que se acuerden y realizará toda investigación preliminar que resulte necesaria en el patrimonio cultural subacuático (artículo 10.5).

Como hemos podido observar, en aguas interiores, archipelágicas o mar territorial la protección del patrimonio cultural sumergido no plantea mayores problemas. Cuando se trata de objetos que se encuentran en la Zona Económica Exclusiva o en la Plataforma Continental ya no

29 Juste Ruiz, José (2003) "La protección internacional de los hallazgos marítimos de interés histórico y cultural”. Anuario de Derecho Marítimo, Vol. XX, p. 63. 
resulta tan sencillo. Se necesita negociación y colaboración entre todos los Estados que resultan afectados, aunque con la coordinación del Estado ribereño en cuestión ${ }^{30}$.

\section{(3.5.) El PATRIMONIO CULTURAL SUbACUÁTiCO SitUAdO EN LA ZONA DE FONDOS MARINOS Y OCEÁNICOS}

Aunque nada se dice en la Convención de 2001 sobre la alta mar, sí aparecen referencias a la Zona, entendida esta como los fondos marinos y oceánicos y su subsuelo fuera de los límites de la jurisdicción nacional ${ }^{31}$, en los artículos 11 y 12 .

El régimen es similar al que hemos explicado en el apartado anterior. Una vez más, todos los Estados Parte tienen que proteger el patrimonio cultural subacuático en la Zona, pero ahora ciñéndose a la Convención y al artículo 149 de la CNUDM, según el cual esos bienes culturales sumergidos que fueron localizados en la Zona van a pertenecer y deberán ser aprovechados en beneficio de la humanidad en su conjunto. Cuando se encuentre patrimonio cultural sumergido o cuando se quiera efectuar una actividad dirigida al mismo, habrá que informar al Director General y al Secretario de la UNESCO del descubrimiento o de las actividades dirigidas al patrimonio cultural subacuático, mientras que en la ZEE y en la PC no era así, porque había que notificarlo al Estado ribereño (artículo 11.2 Convención).

Una vez que se ha informado de la existencia de ese patrimonio cultural subacuático, el Estado Parte pondrá en marcha todos los mecanismos para garantizar su protección. Mientras en la ZEE y la PC era el Estado ribereño quien invitaba a los Estados con vínculos a efectuar consultas y a designar al Estado coordinador, aquí será el Director General de la UNESCO quien asuma esa función (artículo 12.2).

Se vuelve a establecer que no se concederán autorizaciones para actividades dirigidas al patrimonio cultural subacuático situado en la Zona, salvo que dicha autorización sea el resultado del mecanismo previsto de consultas, tal y como se desprende del mismo artículo 12.

Para concluir, debemos señalar que también se ha previsto, al igual que en la ZEE y en la PC, la adopción de medidas viables, de ser necesario, antes de efectuar consultas, con el fin de impedir todo peligro inmediato para el patrimonio cultural subacuático. Ahora bien, mientras en la ZEE y la PC las adoptaba el Estado coordinador, aquí se produce un

\footnotetext{
30 Pueden consultarse, para mayor información, LeAnza, Umberto (1998) “ La zona archeologica marina e la protezione dei beni culturali subacquei”. En La protezione internazionale e la circolacione comunitaria del beni culturali mobili: Napoli: Ed. Paone Pasquale. 
cambio de gran calado y las pueden adoptar todos los Estados (artículo 12.3).

En caso de no cumplirse lo dispuesto en la Convención de 2001, la misma regula en su artículo 17 que los Estados Parte impondrán sanciones en relación a las infracciones que puedan cometerse. No se detalla ningún elenco de sanciones, sino que se indica que deberán ser lo "suficientemente severas" para hacer efectivo el cumplimiento de la Convención y que estas deberán privar a los infractores de los beneficios derivados de las actividades ilícitas, para así evitar que se cometan infracciones.

\section{4) ENTRAda EN VIGOR DE LA CONVENCión DE 2001}

Tal y como apuntamos al inicio de este capítulo, debemos destacar que aunque la Convención fue aprobada por 87 votos a favor, no todos los Estados que votaron favorablemente el día en que se adoptó la han ratificado $^{32}$, aprobado $^{33}$ o aceptado ${ }^{34}$.

El artículo 26 de la Convención de 2001 dispone, por un lado, que debe ser ratificada, aceptada o aprobada por los Estados miembros de la UNESCO y, por otro, que estará sujeta a la adhesión 35 “(a) de los Estados que no sean miembros de la UNESCO pero que sean miembros de las Naciones Unidas o de un organismo especializado del sistema de las Naciones Unidas o del Organismo Internacional de Energía Atómica, así como de los Estados Parte en el Estatuto de la Corte Internacional de Justicia, y de cualquier otro Estado al que la Conferencia General de la UNESCO haya invitado a adherirse a la presente Convención" y "(b) de los territorios que gocen de plena autonomía interna reconocida como tal por las Naciones Unidas, pero que no hayan alcanzado la plena independencia de conformidad con la Resolución 1514 (XV) de la Asamblea General, y que tengan competencia sobre las materias regidas por esta Convención, incluida la de celebrar tratados en relación con ellas". En

32 La ratificación aparece reflejada en los artículos 2.1b, 14.1 y 16 de la Convención de Viena sobre el Derecho de los Tratados de 1969 y por la misma se puede entender que designa el acto internacional a través del cual un Estado manifiesta su consentimiento en obligarse por un Tratado.

33 La aprobación, según el artículo 2.1 b y 14.2 de la Convención de Viena sobre el derecho de los tratados (1969), expresa el consentimiento de un Estado en obligarse por un Tratado. Tiene el mismo efecto jurídico que la ratificación.

34 Al igual que la aprobación, con la aceptación un Estado se obliga por un Tratado.

35 Debe entenderse que la adhesión es un acto mediante el cual un Estado acepta la posibilidad de formar parte de un tratado que ya fue negociado y firmado por otros Estados. Además posee los mismos efectos jurídicos que la ratificación. Naciones Unidas (2001) Manual de Tratado. Preparado por la Sección de Tratados de la Oficina de Asuntos Jurídicos, p. 9. 
todo caso, esos instrumentos de ratificación, aceptación, aprobación o adhesión tienen que ser depositados ante el Director General.

Asimismo, en consonancia con lo anterior, la Convención comenzó a surtir efectos el día 2 de enero de 2009, ya que en el artículo 27 se hacía mención a que la misma entraría en vigor pasados tres meses desde que se depositase el "vigésimo instrumento a que se refiere el Artículo 26". Es decir, hubo que esperar a que 20 Estados depositasen su instrumento de ratificación o aceptación.

Aun aprobándose en el año 2001, tuvieron que pasar casi dos años más para que el primer país, Panamá, ratificase dicho instrumento el día 20 de mayo de 2003. Según pasaba el tiempo y no se llegaba al mínimo de 20 Estados, algunos autores no se mostraban muy partidarios de que entrase en vigor, al menos a corto plazo ${ }^{36}$. A día de hoy siguen sumándose nuevos Estados, tales como Baréin, Hungría y la República Cooperativa de Guyana. Hasta la fecha, solo 48 Estados forman parte de esta Convención: 44 de ellos la han ratificado ${ }^{37}$ y otros 4 la han aceptado ${ }^{38}$.

\section{CONCLUSIONES}

La importancia de la aprobación de la Convención sobre la protección del Patrimonio Cultural Subacuático es notoria, en especial, teniendo en cuenta que hasta la fecha no existía ninguna norma que lo regulase expresamente. Aunque la misma se aprobó en el año 2001, no entró en vigor hasta el año 2009. Ello tiene su razón de ser en base a lo dispuesto en el artículo 27 de la Convención, que señala que entraría en vigor pasados tres meses desde que se depositase el vigésimo instrumento de aprobación al que se refiere el artículo 26, es decir, se necesitaba que 20 Estados aceptasen, aprobasen o ratificasen el texto.

La Convención de 2001 comienza definiendo lo que debe entenderse por Patrimonio Cultural Subacuático y también lo que no debe conside-

36 Carrera Hernández, Francisco Jesús (2005) Protección internacional del patrimonio cultural submarino, p. 80.

37 Panamá, Bulgaria, Croacia, España, Libia, Nigeria, Lituania, México, Paraguay, Portugal, Ecuador, Ucrania, Santa Lucía, Camboya, Cuba, Montenegro, Eslovenia, Granada, Túnez, Eslovaquia, Albania, Bosnia y Herzegovina, Irán, Haití, Jordania, Saint Kitts y Nevis, Italia, Argentina, Honduras, Trinidad y Tobago, República Democrática del Congo, San Vicente y las Granadinas, Namibia, Marruecos, Benin, Jamaica, Palestina, Francia, Antigua y Barbuda, Togo, Bélgica, Bahrein, Hungría, Guyana, Madagascar, Argelia, Guatemala, Arabia Saudita y Ghana.

38 Líbano, Rumanía, Barbados, Gabón, Sudáfrica y Guinea-Bissau. Consultado en la página web oficial de la UNESCO, disponible en:

http://www.unesco.org/eri/la/convention.asp?KO=13520\&language=S [fecha de visita: 20 de mayo de 2016]. 
rarse como tal. Asimismo, en este primer artículo se aportan las definiciones necesarias para entender todo el texto legal.

A continuación se señalan los objetivos y los principios generales, ya que el objeto esencial de la Convención es garantizar y fortalecer la protección del Patrimonio Cultural Subacuático. Estos principios generales se desarrollarán, posteriormente, en las normas que se encuentran en el anexo de la Convención.

Pero si hay algo relevante en la Convención de 2001, es la protección del Patrimonio Cultural Subacuático en los distintos espacios marinos: aguas interiores, archipelágicas, mar territorial, zona contigua, zona económica exclusiva, plataforma continental y zona de fondos marinos y oceánicos.

\section{BIBLIOGRAFÍA}

Álvarez Rubial, Pablo (2012) "Proceso judicial del caso Odyssey en Estados Unidos”. Disponible en: http://noticias.juridicas.com/ conocimiento/articulos-doctrinales/4745-el-proceso-judicial-delcaso-odyssey-en-estados-unidos-/

Aznar Gómez, Mariano José (2004) La protección Internacional del Patrimonio Cultural Subacuático con especial referencia al caso de España. Valencia: Tirant lo Blanch.

Aznar Gómez, Mariano José (2011) "Protección en el espacio iberoamericano del patrimonio subacuático y convenios de la UNESCO". En La UNESCO y la protección internacional de la cultura en el espacio iberoamericano. Madrid: Thomson Reuters.

Bou Franch, Valentín (2009) "La Convención de la UNESCO sobre la protección cultural subacuática”. En La protección jurídico internacional del patrimonio cultural. Especial referencia a España. Madrid: Colex.

Carrera Hernández, Francisco Jesús (2005) Protección internacional del patrimonio cultural submarine. Salamanca: Universidad de Salamanca.

CARDucci, Guido (2002) “The expanding protection of the underwater cultural heritage: The new UNESCO Convention versus existing international law". In The protection of the Underwater Cultural Heritage. Milán: Giuffrè.

Castillo Belinchón, Rocío (2008) "El patrimonio cultural subacuático". ARQVA, Museo Nacional de Arqueología Subacuática: catálogo. Madrid: Ministerio de Cultura-Secretaría General Técnica.

Forrest Craig (2002) A New International Regime for the Protection of Underwater Cultural Heritage, 34 ICLQ 
Fuentes Camacho, Víctor (1993) El tráfico ilícito internacional de bienes culturales. Madrid: Beramar.

Jiménez Piernas, Carlos (2013) "Régimen jurídico de los espacios marinos (I): aguas interiores, mar territorial y zona contigua”. En Díez de Velasco, Manuel (diretor): Instituciones de Derecho Internacional Público. Madrid: Tecnos.

Juste Ruiz, José (2003) "La protección internacional de los hallazgos marítimos de interés histórico y cultural". Anuario de Derecho Maritimo, Vol. XX.

LEANZA, Umberto (1998) "La zona archeologica marina e la protezione dei beni culturali subacquei". En La protezione internazionale e la circolacione comunitaria del beni culturali mobili. Napoli: Ed. Paone Pasquale.

Luna Erreguerena, Pilar (2009) "A importancia do anexo da convenção do patrimonio cultural subaquático". En Patrimônio Cultural $e$ Ambiental. questóes legais e conceituais. São Paulo: Annablume.

Naciones Unidas (2001) Manual de Tratado. Preparado por la Sección de Tratados de la Oficina de Asuntos Jurídicos.

RAU, Markus (2002) "The UNESCO Convention on Underwater Cultural Heritage and the International Law of the Sea". Max Planck Yearbook of United Nations Law, Vol. 6, Max Planck Netherlands: Foundation.

ScovazzI, Tulio (2001) The 2001 UNESCO Convention on the protection of the underwater cultural heritage, 11 IYIL.

STrati, Anastasia (1995) The protection of the Underwater Cultural Heritage: An Emerging Objecting of the Contemporary Law of the Sea. La Haya: Kluwer Law International. 